\title{
Functional expression of aryl hydrocarbon receptor on mast cells populating human endometriotic tissues
}

\author{
Laura Mariuzzi ${ }^{1,4}$, Rossana Domenis ${ }^{1,4}$, Maria Orsaria', Stefania Marzinotto ${ }^{1}$, Ambrogio P Londero ${ }^{2}$, Michela Bulfoni ${ }^{1}$, \\ Veronica Candotti ${ }^{1}$, Andrea Zanello ${ }^{1}$, Maurizio Ballico ${ }^{3}$, Maria C Mimmi ${ }^{3}$, Angelo Calcagno ${ }^{2}$, Diego Marchesoni², \\ Carla Di Loreto ${ }^{1}$, Antonio P Beltrami ${ }^{1}$, Daniela Cesselli ${ }^{1}$ and Giorgia Gri ${ }^{1}$
}

Endometriosis is an inflammatory disease characterized by the presence of ectopic endometrial tissue outside the uterus. A diffuse infiltration of mast cells (MCs) is observed throughout endometriotic lesions, but little is known about how these cells contribute to the network of molecules that modulate the growth of ectopic endometrial implants and promote endometriosis-associated inflammation. The aryl hydrocarbon receptor (AhR), a transcription factor known to respond to environmental toxins and endogenous compounds, is present in MCs. In response to AhR activation, MCs produce IL-17 and reactive oxygen species, highlighting the potential impact of AhR ligands on inflammation via MCs. Here, we investigated the possibility that endometrial MCs promote an inflammatory microenvironment by sensing AhR ligands, thus sustaining endometriosis development. Using human endometriotic tissue (ET) samples, we performed the following experiments: (i) examined the cytokine expression profile; (ii) counted AhR-expressing MCs; (iii) verified the phenotype of AhR-expressing MCs to establish whether MCs have a tolerogenic (IL-10-positive) or inflammatory (IL-17-positive) phenotype; (iv) measured the presence of AhR ligands (tryptophan-derived kynurenine) and tryptophan-metabolizing enzymes (indoleamine 2,3-dioxygenase 1 (IDO1)); (v) treated ET organ cultures with an AhR antagonist in vitro to measure changes in the cytokine milieu; and (vi) measured the growth of endometrial stromal cells cultured with AhR-activated MC-conditioned medium. We found that ET tissue was conducive to cytokine production, orchestrating chronic inflammation and a population of AhR-expressing MCs that are both IL-17 and IL-10-positive. ET was rich in IDO1 and the AhR-ligand kynurenine compared with control tissue, possibly promoting MC activation through AhR. ET was susceptible to treatment with an AhR antagonist, and endometrial stromal cell growth was improved in the presence of soluble factors released by MCs on AhR activation. These results suggest a new mechanistic role of MCs in the pathogenesis of endometriosis.

Laboratory Investigation (2016) 96, 959-971; doi:10.1038/labinvest.2016.74; published online 27 June 2016

Endometriosis is an inflammatory chronic disease characterized by the presence of ectopic endometrial tissue outside the uterus. Endometriosis primarily affects women of reproductive age, with a general population prevalence between 1.5 and $4 \%{ }^{1,2}$ However, the prevalence is $71-87 \%$ among women with pelvic pain and 5-69\% among adolescents with pelvic pain unresponsive to therapy. ${ }^{3}$ The pathogenesis underlying endometriosis initiation and progression has not been fully clarified. Retrograde menstruation could account for the presence of menstrual tissue in the peritoneal cavity; however, its progressive growth relies on defects of the immune system in addition to genetic and epigenetic predispositions that allow endometrial cells to escape apoptosis, evade immune surveillance, invade the mesothelial surface, and acquire vascular supply., ${ }^{4,5}$

Several reports have demonstrated elevated levels of proinflammatory cytokines, such as IL-4, IL-6, IL-8, IL-12, TNF- $\alpha$, and MCP-1/CCL2, in the peritoneal fluid and serum of endometriosis patients. These cytokines could contribute to the proliferation and neoangiogenesis of endometriotic implants but also to progesterone-resistance, which in turn impairs the anti-inflammatory action of progesterone. ${ }^{5}$ Moreover, endometriotic tissues (ETs) reveal abundant inflammatory immune cell infiltrates. However, the role of

\footnotetext{
${ }^{1}$ Section of Surgical Pathology, Department of Medical and Biological Sciences, University Hospital of Udine, Udine, Italy; ${ }^{2}$ Department of Clinical and Biological Sciences, Clinic of Obstetrics and. Gynecology, University Hospital of Udine, Udine, Italy and ${ }^{3}$ Section of Applied Physics, Department of Medical and Biological Sciences, University of Udine, Udine, Italy

Correspondence: Dr G Gri, PhD, Section of Surgical Pathology, Department of Medical and Biological Sciences, University Hospital of Udine, P.le S.Maria della Misericordia 15, Udine 33100, Italy.

E-mail: giorgia.gri@uniud.it

${ }^{4}$ These authors contributed equally to this work.

Received 3 December 2015; revised 26 May 2016; accepted 27 May 2016
} 
specific immune cell subsets and their mediators in the in situ progression of endometrial lesions has not been sufficiently characterized. ${ }^{6}$

Tissue-resident mast cells (MCs) are currently recognized as effector cells in many settings of the immune response, including host defense, immune regulation, allergy, chronic inflammation, and autoimmune diseases. ${ }^{7}$ The pleiotropic functions of MCs reflect their ability to secrete a wide spectrum of preformed or newly synthesized biologically active products in response to multiple signals, with proinflammatory, anti-inflammatory, and/or immunosuppressive properties. ${ }^{8}$ MCs are capable of orchestrating inflammation by modulating the recruitment and function of other immune cells, such as macrophages, granulocytes, and lymphocytes, which have been described to be involved in endometriosis pathogenesis., ${ }^{5-11}$ Diffuse infiltration of degranulated tryptase-positive MCs was observed throughout endometriotic stromal lesions, often close to nerve fibers. ${ }^{12-14}$ Recently, to investigate MC heterogeneity, Paula et al. ${ }^{15}$ demonstrated a significant increase only in the number of chymase-positive cells in abdominal wall endometriotic lesions compared with eutopic endometrium controls. However, how these cells are activated and to what extent they contribute to the network of locally produced cytokines, chemokines, and other mitogenic factors that modulate the growth of the ET and the associated inflammatory profile require further study. ${ }^{16}$

Our group recently discovered that the aryl hydrocarbon receptor (AhR) modulates acute and late MC responses. ${ }^{17}$ AhR, a transcription factor expressed in multiple tissues and in immune cells, is known to respond to environmental toxins, such as 2,3,7,8-tetraclhlorodibenzo-p-dioxin and other polyhalogenated aromatic hydrocarbons, as well as to dietary components and endogenous ligands, including heme and tryptophan metabolites. ${ }^{18}$ AhR influences immune responses and is involved in autoimmune and chronic inflammatory diseases. ${ }^{19-21} \mathrm{AhR}$ is responsible for MC activation in terms of degranulation activity and cytokine responses, ${ }^{17,22,23}$ while its involvement in controlling MC homeostasis remains unclear. ${ }^{22,24} \mathrm{AhR}$ protein has been found in glandular epithelial cells of the human endometrium, and stromal cells cultured from the endometrium in the proliferative phase express AhR in both the cytoplasm and nucleus. ${ }^{25,26}$ Several studies have suggested that AhR is involved in the normal function of the endometrium, possibly by modulating cellular proliferation in response to hormones. ${ }^{27}$ In ETs, AhR mRNA levels are higher than in their healthy eutopic endometrium counterparts. Although dioxin exposure did not affect the expression of AhR in cultured endometrial explants, ${ }^{28,29}$ the effects of AhR activation on ET components by compounds other than dioxin have not yet been studied.

Here, to establish the immunological phenotype of the ET microenvironment, we compared the cytokine profiles of human endometrial explants cultured from both patients and healthy controls. To test the hypothesis that endometrial MCs can sustain endometriosis development through an AhR-mediated pathway, the levels of endogenous tryptophan-derived AhR ligands and the percentage of AhR-positive MCs producing cytokines known to be modulated by AhR were measured in situ. ET explants were exposed to an AhR inhibitor to determine specific changes in the cytokine milieu and last, the growth of endometrial stromal cells cultured with AhR-activated MC-conditioned medium (CM) was assessed.

\section{MATERIALS AND METHODS \\ Tissue Samples}

ETs from patients who had undergone laparoscopic surgery were obtained from the Clinic of Obstetrics and Gynecology, University Hospital of Udine. We included all consecutive women of fertile age at the time of intervention with regular menses and without known endometrial pathology, histological diagnosis of adenomyosis or use of any hormone medication during the year before surgery. This study was conducted according to the Declaration of Helsinki and with Internal Review Board approval (approval number 35/2014). ET representative of stromal and glandular components from ovarian locations were used. As a control, eutopic endometrium from uterine tissues of all women who underwent hysterectomy for leiomyoma and without known endometrial pathology (polyps, dysfunctional uterine bleeding) or histological diagnosis of adenomyosis was used. In the present study, we included 10 women affected by endometriosis and 10 controls. Sample extraction and liquid chromatography (LC) were performed in nine ET samples and nine eutopic endometria of healthy women, whereas cell culture supernatant analysis was performed in four ET samples and four eutopic endometria of healthy women due to the paucity of available tissue from the remainder of the samples.

\section{ET Culture and Multiplex ELISA}

Immediately after surgery, ETs and healthy eutopic endometrium samples were brought to the laboratory of Surgical Pathology. After removal of hemorrhagic tissues, the areas macroscopically recognized as endometrial mucosa were gently teased away from the underlying tissue. All samples were cut into $2-3 \mathrm{~mm}^{3}$ uniform explants with a sterile scalpel blade and cultured in 48 -well plates at $37^{\circ} \mathrm{C}$ in a humidified atmosphere of $95 \%$ air and $5 \% \mathrm{CO}_{2}$ in $0.5 \mathrm{ml}$ of complete RPMI-1640 medium supplemented with 10\% FBS (Euroclone, Milano IT). To culture uniform type of explants and to avoid the inclusion of ovarian tissue, frozen sections of zerotime control tissues from each specimen and formalin-fixed and paraffin-embedded of $48 \mathrm{~h}$-incubated tissues from organ cultures were used to assess tissue architecture and composition (data not shown). Tissue culture medium harvested after $48 \mathrm{~h}$ was centrifuged for $5 \mathrm{~min}$ at $2200 \mathrm{~g}$, and supernatants were stored at $-80^{\circ} \mathrm{C}$. Cytokine, chemokine, and growth factor concentrations were measured by quantitative cytokine 
assays using Bioplex Pro human cytokine standard 17-plex panels according to the pre-optimized protocol provided by the manufacturer. The data were collected and analyzed using a Bio-Rad BioPlex 200 instrument equipped with Bio-Plex Manager software version 6.0 (all from Bio-Rad Laboratory, Hercules, CA, USA).

To test the effect of an AhR inhibitor on ET, endometriotic explants were incubated for $48 \mathrm{~h}$ with complete $10 \%$ FBS RPMI-1640 medium containing $15 \mu \mathrm{M} \alpha$-Naphthoflavone (ANF; Sigma-Aldrich Company Ltd, Gillingham, UK), a specific AhR antagonist, before collecting tissue culture medium, and performing a Bioplex Pro ELISA as described above. ANF was dissolved in $0.1 \%$ dimethyl sulfoxide, which was also added to the control samples.

\section{Antibodies, Dilution, and Incubation}

The following panel of commercially available primary antihuman Abs was included in this study: mouse MC tryptase (clone AA1, M7052, Dako, Glostrup DK; dilution for immunohistochemistry (IHC) 1:500, and incubation $1 \mathrm{~h}$ at $37^{\circ} \mathrm{C}$ ); mouse MC tryptase (clone AA1, ab2378, Abcam, Cambrige UK; dilution for IF 1:600, incubation $2 \mathrm{~h}$ at $37^{\circ} \mathrm{C}$ ); mouse MC chymase (clone CC1, MCCXMS, Aczon Biotech, Bologna, IT; dilution for IHC 1:50, incubation $1 \mathrm{~h}$ at $37^{\circ} \mathrm{C}$ ); mouse AhR (clone RPT1, GTX22770, GeneTex, Irvine CA, USA; dilution for IHC 1:100, incubation $16 \mathrm{~h}$ at $4{ }^{\circ} \mathrm{C}$ ); rabbit AhR (LS-A3391, LifeSpan BioSciences, Seattle WA USA; dilution for IF 1:30, incubation $16 \mathrm{~h}$ at $4{ }^{\circ} \mathrm{C}$ ); rabbit IDO1 (clone M80, sc-25809, Santa Cruz Biotechnology, Dallas TX, USA; dilution for IHC $1: 400$, incubation $1 \mathrm{~h}$ at $37^{\circ} \mathrm{C}$ ); goat IL-17 (AF-317-NA, R\&D System, Minneapolis, MN, USA; dilution for IF $1: 25$, incubation $3 \mathrm{~h}$ at $37^{\circ} \mathrm{C}$ ); rat IL-10 (clone JES3-9D7, 14-7108, eBiosciences, San Diego CA, USA; dilution for IF 1:80, incubation $3 \mathrm{~h}$ at $37^{\circ} \mathrm{C}$ ).

Secondary conjugated Abs for IF were: anti-mouse Alexa Fluor 488 (Abcam; dilution 1:800), anti-rabbit 649 (dilution 1:400), and anti-rat DyLight 549 (dilution 1:800), both from Jackson Immunoresearch Europe Ltd. (Suffolk UK), and antigoat Alexa Fluor 555 (Invitrogen Thermo Fisher Scientific Inc. Waltham, MA USA; dilution 1:600). Slides were incubated with the fluorescent-labeled secondary Abs for $1 \mathrm{~h}$ at $37^{\circ} \mathrm{C}$.

\section{Immunohistochemistry and Immunofluorescence (IF)}

IHC was performed on $3.5 \mu \mathrm{m}$ formalin-fixed paraffinembedded slides. The slides were deparaffinized and pretreated for epitope retrieval using EnVision FLEX citrate buffer, $\mathrm{pH}$ 6.0, in PT Link and then placed in an automated Autostainer Link 48 immunostainer (all from Dako, Glostrup, Denmark).

Sections were incubated with primary antibodies (Abs; see paragraph above) and detected using EnVision FLEX system (Dako). Images were obtained using a Leica DMD108 digital microimaging network (Leica Microsystems, Wetzlar, Germany).
Semiquantitative analysis of the IHC staining was performed independently by two pathologists (LM and MO), and glands were considered separately from stroma. Staining was evaluated as follows: percentage of positive cells, intensity of the positivity (evaluated as strong 3 , moderate 2 , and weak 1 ) and $\mathrm{H}$-score (product of percentage of positivity and intensity; ranging from 0 to 300 as previously described ${ }^{30}$ ).

For IF, after incubation with primary Abs (see paragraph above), PBS-washed sections underwent incubation with the fluorescently labeled secondary Abs. Staining specificities were assessed by substituting primary antibodies with isotype controls. The reliability of the triple-staining procedure was evaluated by comparing the three single stains with the triple fluorescent stain in four consecutive sections. Slides were mounted with Vectashield containing DAPI (Vector Laboratories, Burlingame CA, USA) and visualized using a fluorescence-imaging microscope (Leica DMI 6000B) coupled to a CCD camera (Leica DFC350FX). The images were analyzed and composed using Leica LAS AF lite (Leica Microsystems), Adobe Photoshop (Adobe Systems Incorporated, San Jose, CA), and ImageJ software (Open source software, https://imagej.nih.gov/ij/). The percentage of tryptase/Ahr double-positive or tryptase/Ahr/IL-17 and tryptase/ Ahr/IL-10 triple-positive cells was determined by counting double- or triple-positive cells among tryptase-positive cells with a $\times 40$ oil immersion objective lens (numerical aperture: 1.25). All analyses were performed by two independent, blinded observers (GG and RD), and the average counts of the two observers were used.

To test the sensitivity and specificity of the AhR antibody LS-A3391 to AhR protein and not to AhR nuclear translocator (ARNT), different human cell lines ARNT-positive were stained by IF. U87 glioblastoma and HMC-1 MC lines resulted in AhR-positive staining, whereas no positive signal was found in K562 myelogenous leukemia or Jurkat leukemic T-cell lines (Supplementary Figure 1), in accordance with the results reported by the Human Protein Atlas (http://www. proteinatlas.org/) and in ref. 31. Our results indicate that the antibody used herein does not cross react with ARNT.

\section{Sample Extraction, Liquid Chromatography and Electrospray lonization-Mass Spectrometry (ESI-MS)}

Specimens from healthy endometrium and ETs were collected, immediately frozen in liquid nitrogen and then stored at $-80^{\circ} \mathrm{C}$ until metabolite extraction and analysis. The frozen samples, ranging between 40 and $200 \mathrm{mg}$, were placed in $2 \mathrm{ml}$ Eppendorf tubes with $1.5 \mathrm{ml}$ of a methanol/water mixture (1/1) and a metal sphere with a 5-mm diameter. The samples were then homogenized by two 5-min cycles of $50-\mathrm{Hz}$ vibrations (TissueLyser, Qiagen, Redwood City, CA, USA) with an intermediary cooling cycle on dry ice. After centrifugation at $16000 \mathrm{~g}$ for $10 \mathrm{~min}$, each supernatant containing the water-soluble metabolites was dried in a vacuum desiccator at room temperature for $2.5 \mathrm{~h}$. The obtained residue was re-dissolved in $20 \mu \mathrm{l}$ water, and $1.6 \mathrm{ml}$ of 
methanol was added to remove contaminating proteins. Each solution was centrifuged at $16000 \mathrm{~g}$ for $10 \mathrm{~min}$; the supernatant was then divided into four aliquots, vacuum-dried, and stored at $-80^{\circ} \mathrm{C}$ until LC/ESI-MS analysis. The tissue pellet was suspended in $1.6 \mathrm{ml}$ of a dichloromethane/methanol mixture (3/1) and homogenized by two 5-min cycles of $50-\mathrm{Hz}$ vibrations with an intermediary cooling cycle on dry ice. After centrifugation at $16000 \mathrm{~g}$ for $10 \mathrm{~min}$, the supernatant was divided into four aliquots, dried under vacuum, and stored at $-80^{\circ} \mathrm{C}$. Each aliquot containing the hydrophilic metabolites was dissolved in milliQ $\mathrm{H}_{2} \mathrm{O}(200 \mu \mathrm{l})$, and the internal standard (2'-deoxy-adenosine) was added before further dilution with milliQ $\mathrm{H}_{2} \mathrm{O}(0.1 \% \mathrm{HCOOH})$. The final internal standard concentration was $12 \mu \mathrm{M} ; 5 \mu \mathrm{l}$ of each diluted solution (equivalent to the extract from $80 \mu \mathrm{g}$ of starting tissue) was injected into the LC/ESI-MS system. The analysis of the mixtures was performed with a hybrid QqTOF mass spectrometer AB Sciex QSTAR (Applied Biosystems, Foster City, CA, USA) equipped with an Agilent 1100 Series micro HPLC (Agilent Technologies, Santa Clara, CA, USA). A reversed phase column Jupiter C4, $150 \times 0.5 \mathrm{~mm}, 5 \mu \mathrm{m}$, $300 \AA$ (Phenomenex, Torrance, CA. USA) was used for chromatographic separation; the gradient scheme was: 0-10 min equilibration at $10 \% \mathrm{~B}, 10-45$ min linear gradient from $10 \%$ to $90 \% \mathrm{~B}$, and $45-55$ min elution at $90 \% \mathrm{~B}$, where A and $\mathrm{B}$ were $\mathrm{H}_{2} \mathrm{O}$ MilliQ (0.1\% Formic Acid) and $\mathrm{CH}_{3} \mathrm{CN}$ (0.1\% Formic Acid), respectively, and the flux was $10.0 \mu \mathrm{l} / \mathrm{min}$.

Mass spectra were recorded in positive ion mode. The pseudo-MRM (Multiple Reaction Monitoring) method was developed in-house; each acquisition cycle included one fullscan MS spectrum and three specific product ion MS/MS spectra for the detection of tryptophan, kynurenine, and the internal standard. ESI-MS acquisition parameters for both MS and product ion scans were as follows: nebulizer gas (GS1) and curtain gas (CUR) set at 20.00 and $15.00 \mathrm{psi}$, respectively; declustering potential (DP), focusing potential (FP) and secondary DP set at 40,230 , and $15 \mathrm{~V}$, respectively, to minimize in-source fragmentation; ion spray voltage set at $5.50 \mathrm{kV}$. After optimization of MS/MS product ion scan for the target metabolites, the collision energy was set at $15 \mathrm{~V}$. Selective narrow windows, with a width of $2 \mathrm{~m} / \mathrm{z}$ units, were fixed for TOF detection to include the most intense fragment ions obtained by MS/MS scan (187-189 amu, 191-193 amu, and 135-137 amu for tryptophan, kynurenine, and internal standard, respectively).

The absolute concentration of tryptophan and kynurenine in the analyzed samples was based on standard compound calibration curves (Sigma-Aldrich). The final results, presented in Figure 2, were the ratio of metabolite content/ bioptic tissue mass (ng/g or $\mu \mathrm{g} / \mathrm{g}$ ), which allows a comparison among samples.

\section{Culture of Stromal Cells From Human Endometrium}

To isolate and culture stromal cells from normal endometrium, taken at days $4-6$ of the cycle (late menstrual) in the early proliferative phase, we used a protocol optimized for culturing stromal cells from human tissues with minor modifications. ${ }^{32-34}$ In brief, tissue fragments were enzymatically dissociated using $0.025 \%$ collagenase II for $10 \mathrm{~min}$ at $37^{\circ} \mathrm{C}$ (Worthington, Lakewood, NJ). After neutralization of the enzyme, the solution was centrifuged at $600 \mathrm{~g}$ for $10 \mathrm{~min}$ and filtered to obtain cells $<70 \mu \mathrm{m}$ in diameter (Millipore). Freshly isolated cells $\left(1.5 \times 10^{6}\right)$ were plated onto human fibronectin (Sigma-Aldrich)-coated 100-mm dishes (Corning BV life sciences, Corning, NY) in proliferation medium (60\% low glucose DMEM (Invitrogen), 40\% MCDB-201, $1 \mathrm{mg} / \mathrm{ml}$ linoleic acid-BSA, $10^{-9} \mathrm{M}$ dexamethasone, $10^{-4} \mathrm{M}$ ascorbic acid-2 phosphate, $1 \times$ insulin-transferrin-sodium selenite (all from Sigma-Aldrich), $2 \%$ fetal bovine serum (StemCell Technologies), $10 \mathrm{ng} / \mathrm{ml}$ human PDGF-BB, and $10 \mathrm{ng} / \mathrm{ml}$ human EGF (both from Peprotech EC)), as in ref. 32-34. The medium was replaced every 4 days. Once cells reached 70-80\% confluence, they were detached by TrypLE Express (Invitrogen) and re-plated at a density of $2 \times 10^{3} / \mathrm{cm}^{2}$. To validate the stromal cultures from human endometrium, we have performed flow cytometric and immunofluorescence analysis. At passage 3, all cells expressed vimentin, but not cytokeratins by immunostaining. By flow cytometric analysis, stromal cells were found to express several stromal cells biomarkers, CD29, CD90, CD44, CD49, and CD105. Cells were negative for epithelial markers EPCAM and E-CAD, and did not show the expression of CD34, CD38, and CD45, which are specific markers for hematopoietic stem cells and leukocytes, respectively (Supplementary Figure 2).

\section{Growth Kinetics and Preparation of MC-CM}

The cell population doubling time (PDT) was calculated by plating cells at the third passage at a density of $2 \times 10^{3}$ cells/ $\mathrm{cm}^{2}$ into 96-well plates (BD FalconTM) in MC-CM, obtained as follows: $1 \times 10^{6}$ cells $/ \mathrm{ml}$ of the human MC line HMC- 1 were cultured for $48 \mathrm{~h}$ in the absence or presence of FICZ $(300 \mathrm{nM})$ or, as a positive control, phorbol 12-myristate 13 -acetate (PMA, $1 \mathrm{ng} / \mathrm{ml})$ and ionomycin $(200 \mathrm{ng} / \mathrm{ml}),{ }^{35}$ all from Sigma-Aldrich. HMC-1-derived medium was diluted (1:1) in stromal cell culture medium before incubation with stromal cells. CM was replaced every 4 days, and images of Hoechst 33342-labeled cells were acquired at different time points (1-2-3-5days) using a Leica DMI 6000B microscope connected to a Leica DFC350FX camera (Leica Microsystems) and equipped with $a \times 5$ objective lens (numerical aperture: 0.12). Cell counts were performed using ImageJ. Experiments were performed in triplicate. PDT was calculated during the log-phase of growth.

\section{Statistical Analysis}

The data were analyzed using $\mathrm{R}$ (version 3.1.1), and $P<0.05$ was considered significant. All $P$-values presented are for a two-tailed test. The normality of variables was tested with the Kolmogorov-Smirnov test. Parametric data were described with the mean value and its s.d. or $95 \%$ confidence interval, 
Table 1 Population description

\begin{tabular}{|c|c|c|c|}
\hline & Controls & ETs & $P$ \\
\hline Median age of women in years (range) & $47(45-49)$ & $45(44-47)$ & 0.476 \\
\hline \multicolumn{4}{|l|}{ Phases } \\
\hline Follicular phase & $60 \%(6 / 10)$ & $60 \%(6 / 10)$ & 1.000 \\
\hline Luteal phase & $40 \%(4 / 10)$ & $40 \%(4 / 10)$ & 1.000 \\
\hline \multicolumn{4}{|l|}{ Indication for surgery } \\
\hline Ovarian mass & - & $70 \%(7 / 10)$ & - \\
\hline Chronic pelvic pain & - & $30 \%(3 / 10)$ & - \\
\hline \multicolumn{4}{|l|}{ ASRM stage } \\
\hline \multicolumn{4}{|l|}{ । } \\
\hline$\|$ & - & $30 \%(3 / 10)$ & - \\
\hline III & - & $40 \%(4 / 10)$ & - \\
\hline IV & - & $30 \%(3 / 10)$ & - \\
\hline
\end{tabular}

The backgrounds of controls $(n=10)$ and ovarian ETs $(n=10)$ used in this study are shown.

whereas non-parametric data were presented with the median value and interquartile range (IQR). For univariate analysis, the following statistical tests were applied: the $t$-test or Wilcoxon test for continuous variables and the Fisher exact or $\chi^{2}$ test for categorical variables. For the comparison of more than two groups (growth kinetics in the presence of CM), a Friedman test followed by Dunn's test was applied.

\section{RESULTS}

\section{Population Characteristics}

The women who underwent surgery for endometriosis had a median age of 45 years (44-47), whereas controls had a median age of 47 years $(45-49)(P=0.476)$. All the ETs analyzed were from ovarian endometriomas, and no significant differences were registered in the cycle phase at the time of surgery between cases and controls (Table 1).

\section{Inflammatory Profiles in Explant Cultures of Human Endometrium}

The serum and peritoneal fluid of women with endometriosis have been reported to contain high levels of several proinflammatory cytokines. ${ }^{36,37}$ Thus, to characterize the cytokine milieu present at the ET site, we analyzed a broad range of cytokines produced by healthy eutopic endometrium samples and ETs (Table 2). ETs were characterized by a significant increase in IL-4, IL-10, IL-12, IL-17, IFN- $\gamma$, MCP-1/CCL2, and MIP-1 $\beta / C C L 4$ production compared with eutopic endometrium samples and a significant reduction of GM-CSF and TNF- $\alpha$ (Table 2). This result indicates that ETs are enriched in numerous cytokines and chemokines that could facilitate chronic disease progression.

\section{Expression of AhR in MCs within ETs}

Altered immune cell function might explain the observed variation in the ET production of cytokines and MCs could contribute to this pattern. As MCs can be activated by AhR, ETs were stained for the presence of this receptor. As reported in the literature, ${ }^{26,38} \mathrm{AhR}$ positivity was distributed in cells of the stroma and in the inflammatory infiltrate (Figure 1a). Positive cells resembling the characteristic granule-rich MC profile were observed (Figure 1b); indeed, immunofluorescence assays confirmed the co-localization of AhR and tryptase in 67\% (IQR 57-76\%) of MCs present within ovarian ETs and in $89 \%$ of MCs in healthy controls (IQR $86-95 \%)(P<0.05$; Figures $1 \mathrm{c}$ and $d)$. Not all MCs populating ETs were AhR-positive, in accordance with previous works showing that exposure to AhR agonists causes AhR-expressing cells to downregulate the receptor. ${ }^{17,39}$

\section{Enhanced Expression of the AhR-Ligand Kynurenine and IDO1 in ETs Compared with Eutopic Endometrium}

AhR can be triggered by the tryptophan metabolite kynurenine, which can activate MCs. ${ }^{23}$ Thus, we measured the tissue concentrations of this AhR ligand in eutopic endometrium and ETs. Kynurenine was highly expressed in ETs compared with controls (Figure 2a; $P<0.05$ ). Accordingly, tryptophan was impaired in the same endometriotic specimens (Figure $2 \mathrm{~b} ; P<0.05$ ); thus, the ratio between kynurenine and tryptophan was significantly higher in ETs than in the eutopic endometrium of controls (median of $86.45 \mathrm{ng} / \mu \mathrm{g}$, IQR $50.56-105.93$ vs $1.76 \mathrm{ng} / \mu \mathrm{g}$, IQR $1.52-1.88 ; P<0.05$; Figure 2c).

It was recently shown that IDO1, the enzyme that catalyzes the degradation of tryptophan to kynurenine, is highly expressed in endometriosis-derived eutopic and ectopic endometrial stromal cells compared with endometriosis-free normal stromal cells. ${ }^{40}$ Indeed, IHC analysis of our samples demonstrated that IDO1 positivity was confined to vascular endothelial cells in the control samples (Figure 2d, i and ii), whereas the staining was extended to stromal cells in ETs (Figure 2d, iii). The staining intensity of IDO1, represented by the $\mathrm{H}$-score, was significantly higher in the stromal component of ETs (110, IQR 100-140) than in the eutopic endometrial stroma of controls (0, IQR $0-5) \quad(P<0.05$; Figure 2d, iv).

Altogether, these results indicate that signaling through the AhR pathway in ETs is likely to occur.

\section{AhR-Positive MCs in ETs Express IL-17 and IL-10 Cytokines}

We have shown that AhR-activated MCs produce IL-17, a critical player in chronic inflammation and autoimmunity, the proinflammatory cytokines IL- 6 and IL-13 and the immunomodulatory cytokine IL-10. ${ }^{17}$ To establish the phenotype of 
Table 2 Different cytokine production between the eutopic endometrium of healthy women (controls) and ovarian ETs

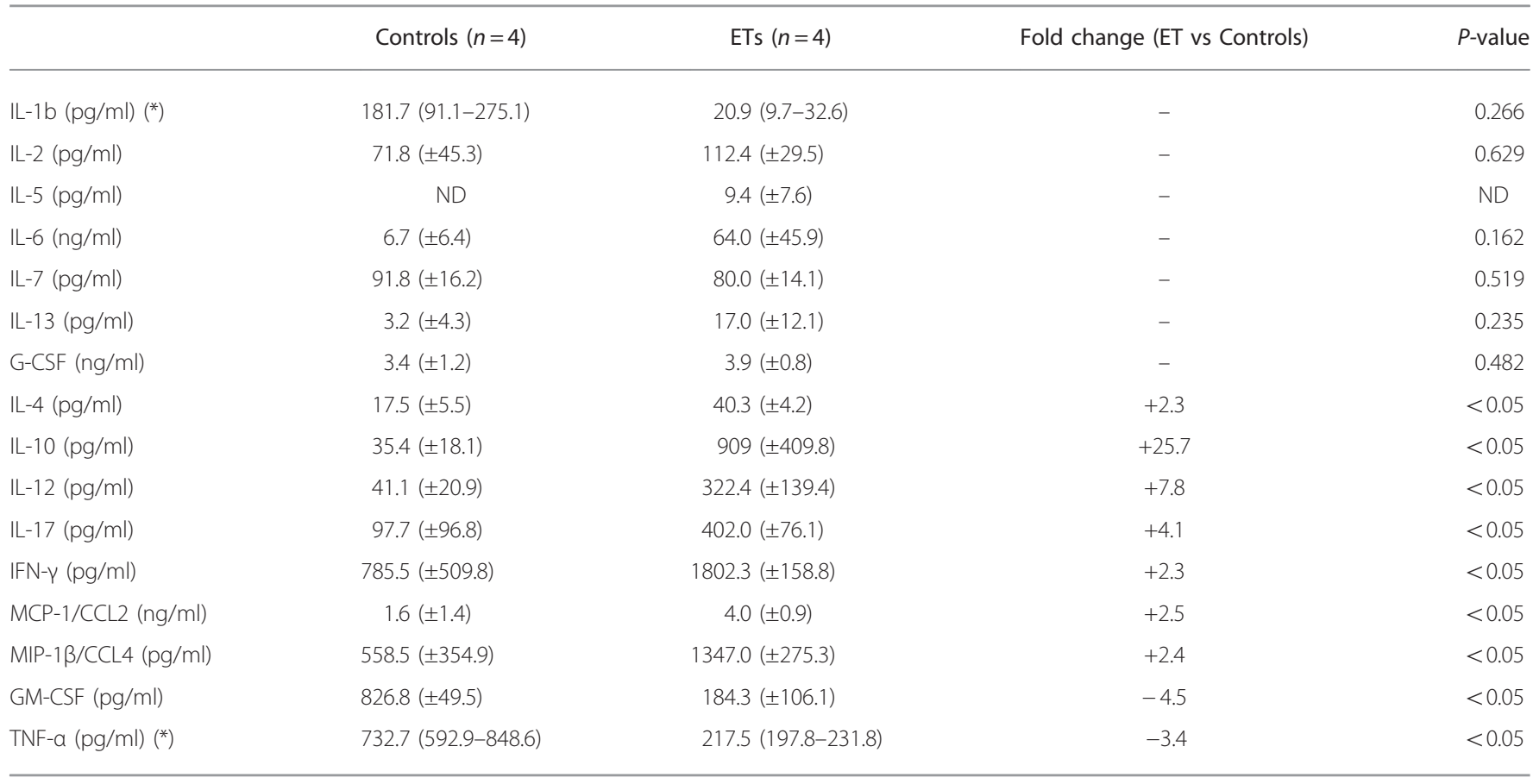

Cytokine production was evaluated in the supernatants of healthy endometrium or ETs cultured in complete medium for $48 \mathrm{~h}$. The data are presented as the mean ( \pm s.d.); $P$-values refer to $t$-test or are presented as the median (IQR), and $P$-value refers to Wilcoxon test $(*)$. ND, not detectable.

MCs within ETs, the presence of AhR-positive MCs, as well as the number of AhR-positive cells expressing IL-17, was assessed in ET and control specimens by triple immunofluorescence in situ (Figures 3a and b). The results showed colocalization of tryptase, AhR and IL-17 in 54\% of MCs in the ET samples (IQR 44-64\%), whereas this value was decreased to $2.5 \%$ (IQR 2-4\%) in healthy controls due to the limited expression of IL-17 (Figure 3c). To establish whether MCs represent an important source of IL-17 in ETs, IL-17 cells expressing the MC-specific marker tryptase were counted among the total IL-17-positive cells (Figure 3d). We observed that $63.0 \%$ (IQR $49.0-74.5 \%$ ) of IL-17 cells were also tryptase-positive.

To determine whether chymase-positive MCs express AhR in a similar manner to tryptase-positive MCs, we first stained serial ET sections with Abs recognizing both enzymes. Then, AhR, chymase, and IL-17 were concurrently evaluated in immunofluorescent staining. In our hands, the chymase staining was less diffuse than tryptase (Figures $4 \mathrm{a}$ and b). Tryptase- and chymase-positive cells showed similar expression patterns and were equally present in ETs (Figure 4c). Thus, we cannot exclude the possibility that MCs in ETs are $\mathrm{MC}_{\mathrm{TC}}$. Notably, we showed that chymase-positive cells do express AhR and that they are also IL-17-positive (Figure 4d).

As AhR signaling promotes MC-derived IL-10, ETs, and controls were stained to highlight the possible presence of IL-10-producing AhR-positive MCs (Figures 5a and b). Indeed, we observed a significant co-localization of $\mathrm{MC}$ - trypatase, AhR, and IL-10 in 55\% of MCs (IQR 53-73\%) within ETs but also in 33\% (IQR 31-37\%) of MCs in control endometrium tissues. Nevertheless, the increase was significant $(P<0.05$; Figure 5c). In ETs, 50.2\% (IQR 41.4-62.1\%) of IL-10-positive cells co-expressed the MC tryptase (Figure 5d), suggesting that MCs contain at least half of the total amount of the two analyzed cytokines. Moreover, by immunofluorescence, we examined whether IL-10 and IL-17 are both present in the same MCs or in different MC populations. We found that 99\% (IQR 98.0-99.0\%) of MCs in ET tissues $(n=10)$ co-expressed these two cytokines (Supplementary Figure 3).

\section{ET Microenvironment Response to Exposure to an AhR Antagonist}

To prove that the AhR pathway plays a role in modulating the cytokine and chemokine milieu of ETs and to counteract the observed increase in the AhR activating agent kynurenine, four explant cultures of patients were exposed to a single dose of $15 \mu \mathrm{M}$ ANF, an AhR antagonist. ${ }^{41}$ After $48 \mathrm{~h}$, the cytokines released in the supernatants were measured and compared with untreated control specimens. A broad downregulation of IL-4, IL-10, IL-17, IFN- $\gamma$, MCP-1/CCL2, and TNF- $\alpha$ resulted on treatment with ANF, although only IL-12 and MIP-1 $\beta$ / CCL4 levels were significantly reduced in our limited sample size (Figure 6a).

To confirm that AhR-activated MCs are able to release molecules that could affect the growth of endometrium 
a

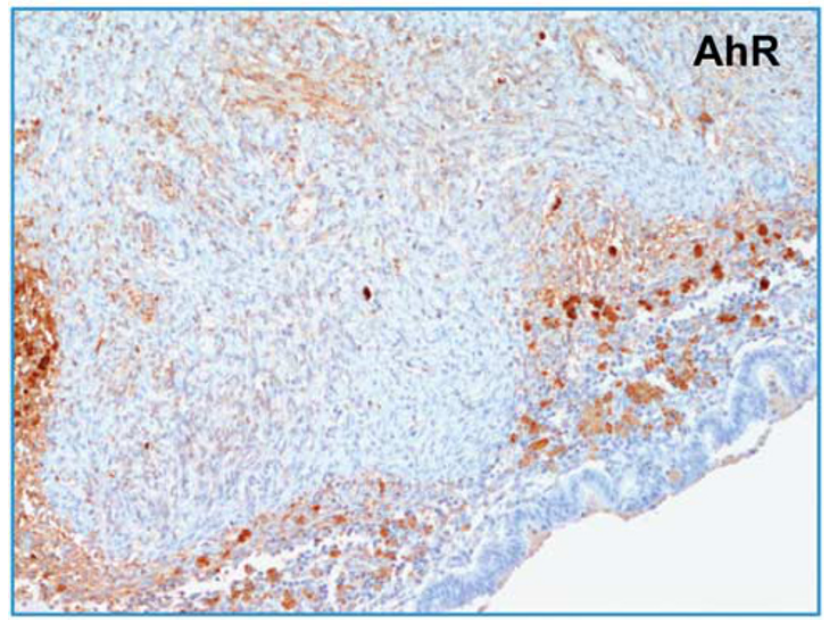

c

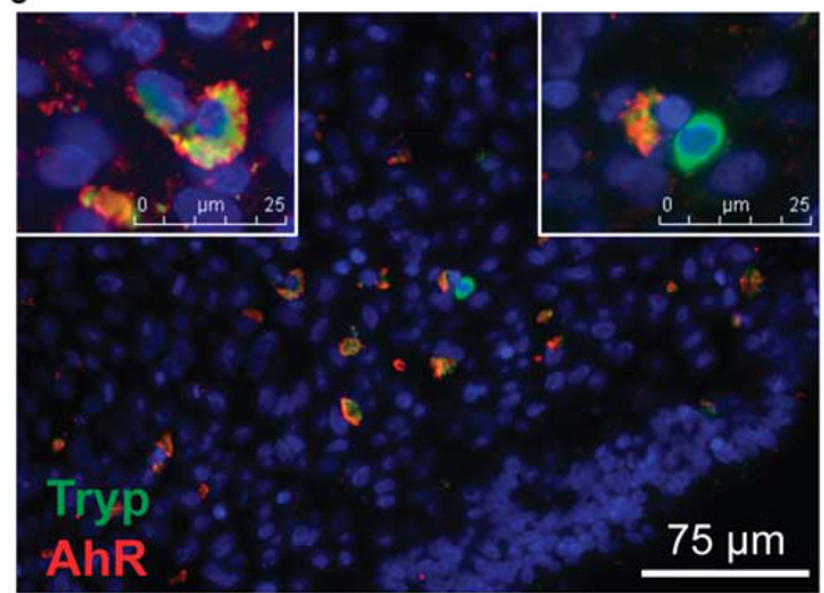

b

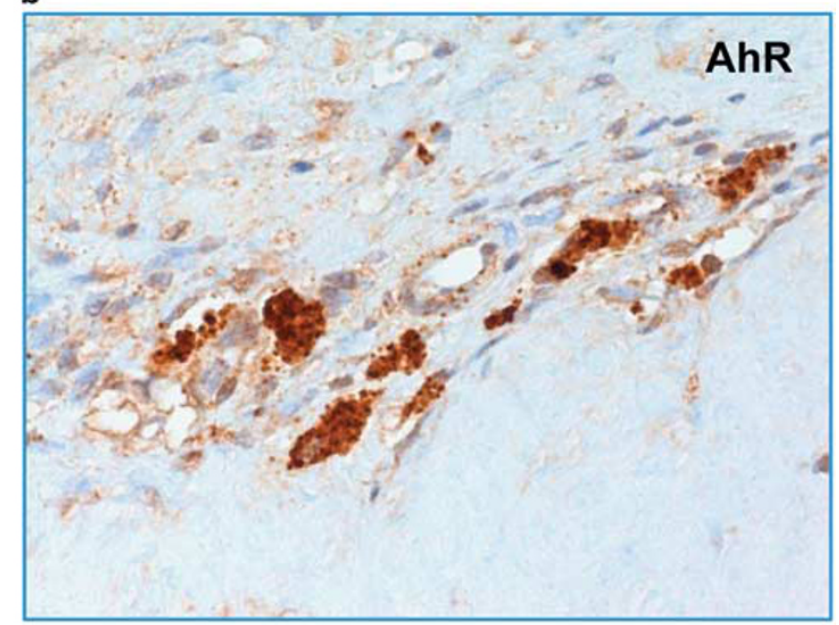

d

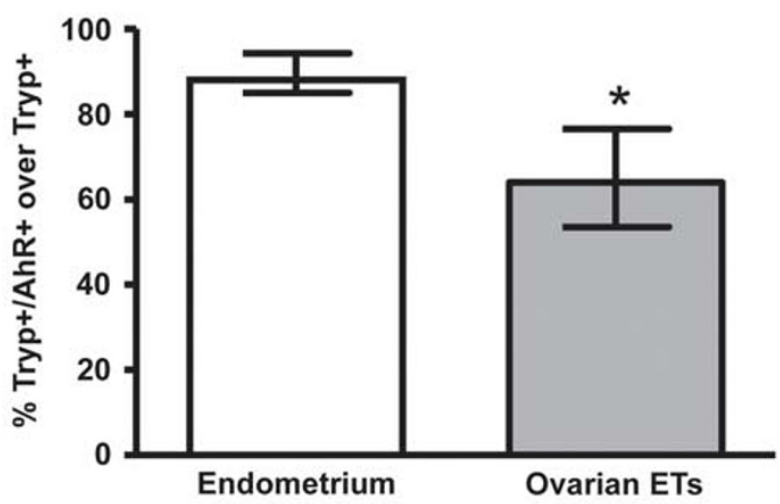

Figure 1 Mast cells (MCs) populating endometriotic tissues (ETs) express aryl hydrocarbon receptor (AhR). (a and b) Immunohistochemical localization of AhR protein in human ETs. Magnification, $\times 200$ and $\times 400$. (c) Double-marker immunofluorescence analysis of AhR and tryptase (Tryp) in sections from ETs (double staining: Tryp green, AhR red). Bars $75 \mu \mathrm{m}$ and $25 \mu \mathrm{m}$ (inset). (d) Percentage of Tryp/AhR (Tryp ${ }^{+} /$AhR $^{+}$) double-positive cells over total Tryp single-positive cells ( $n=10 /$ group). Cells were detected and counted from $10 \times 400$ high-power microscopic fields in each individual sample. Endometrium median 89\% (IQR 86-95\%); ovarian ET median 67\% (IQR 57-76\%). * $P<0.05$.

components, we cultured stromal cells from three tissue samples with a CM obtained on exposure of the HMC-1 MC line to the AhR-activating ligand FICZ (Figure 6b). As a control, PMA, and ionomycin, a stimulus known to induce the expression of several cytokines, was used. ${ }^{35}$ Culturing endometrial stromal cells with CM from FICZ-treated MCs led to a significant decrease in the PDT from 37.7 to $31 \mathrm{~h}$ $(P<0.05)$, similar to what we observed with $\mathrm{CM}$ from $\mathrm{PMA} /$ ionomycin-treated MCs (from 37.7 to $30.6 \mathrm{~h}, P<0.05$; Figure $6 \mathrm{~b})$.

Altogether, our results suggest a likely involvement of the AhR pathway, and particularly of AhR-expressing MCs, in the chronic inflammation associated with endometriosis. These results open a new perspective in the treatment of this disease.

\section{DISCUSSION}

The present study is the first to analyze the phenotypic profile of MCs populating ETs in terms of cytokine production instead of granule content or tissue distribution. Furthermore, we envisaged that endometriotic MCs could be activated on AhR signaling to secrete regulatory cytokines. Indeed, analysis of the inflammatory pattern of ETs showed increased cytokine production compared with the healthy eutopic endometrium obtained from controls. MCs appear to significantly contribute to the observed differences in inflammation. In fact, the majority of MC-trypatase or MC-chymase co-localized with AhR and IL-17 or IL-10 cytokines, and they accounted for half of the population expressing these cytokines within ET lesions. Moreover, there was a significantly increased $\mathrm{H}$-score of the tryptophan- 
a

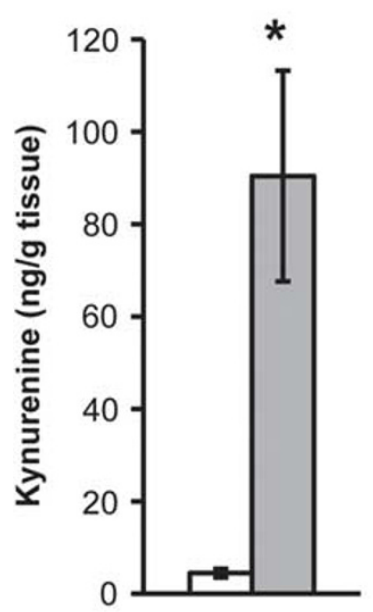

b

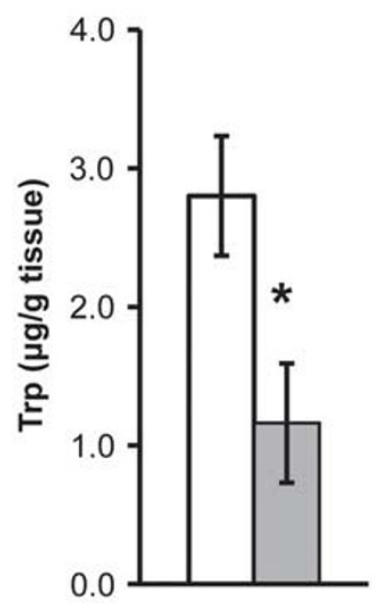

C

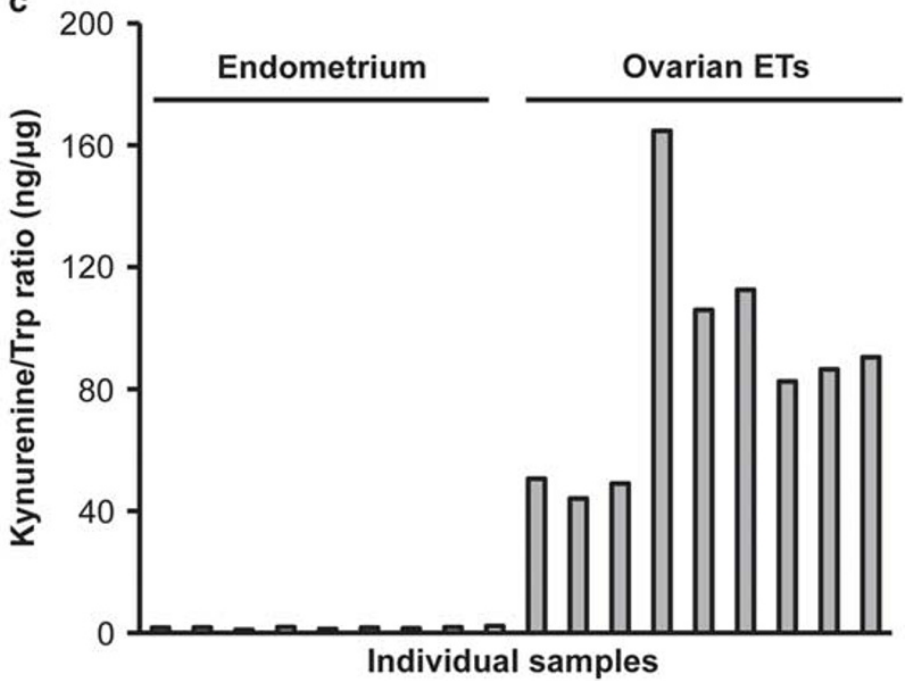

d
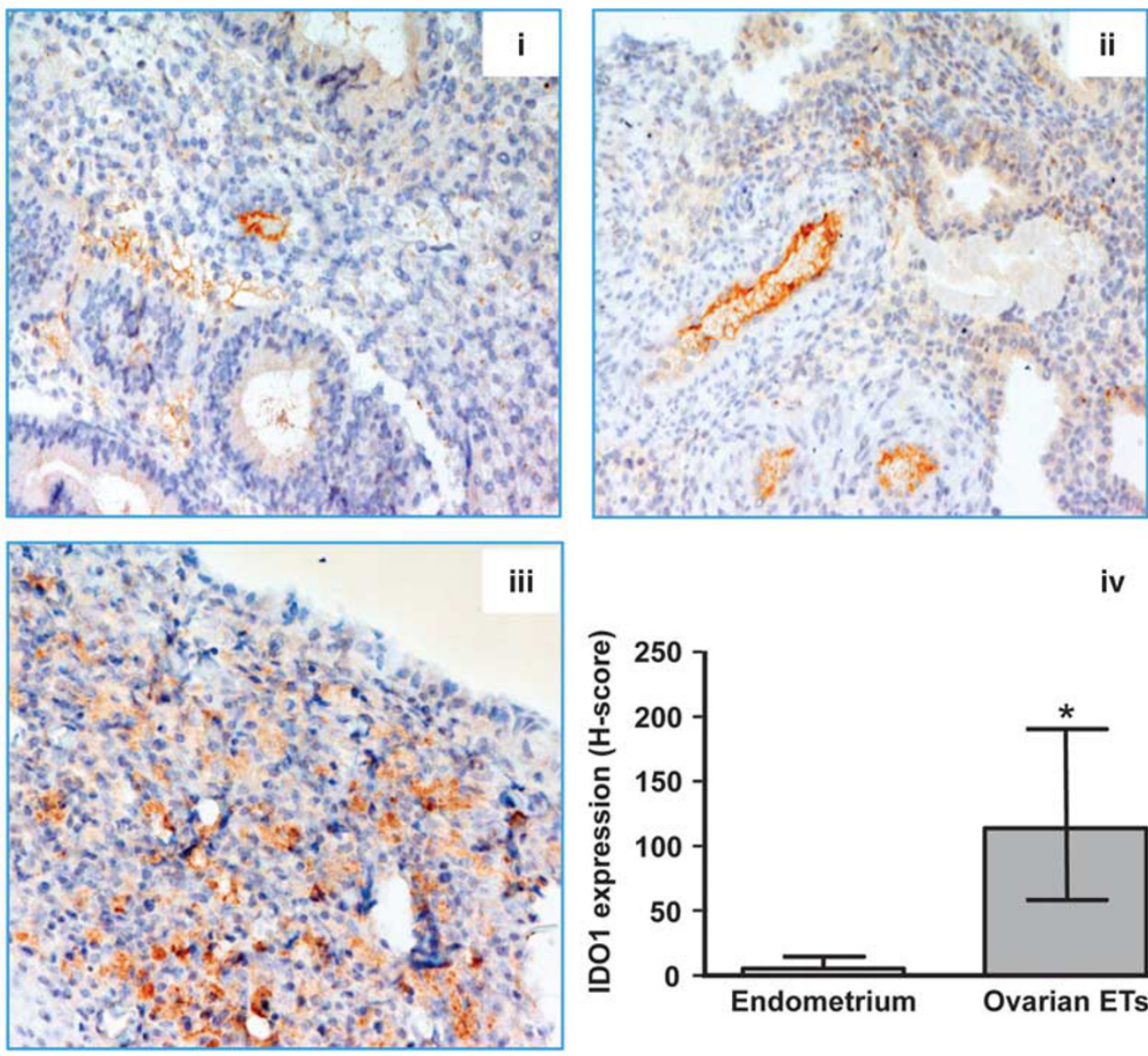

ii

iv

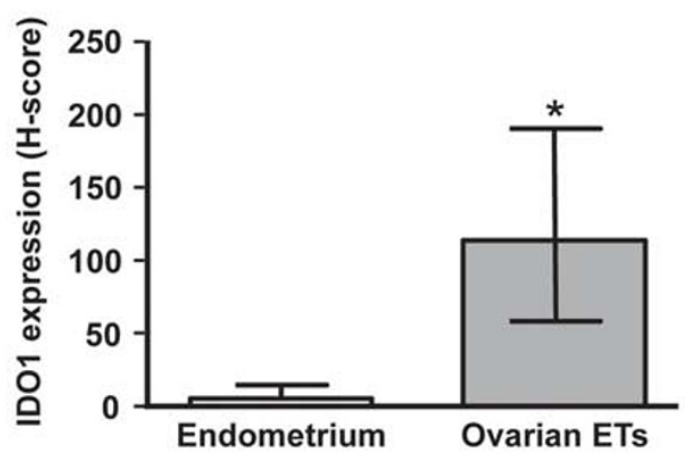

Figure 2 Enrichment in the aryl hydrocarbon receptor (AhR) ligand kynurenine and the tryptophan-metabolizing enzyme IDO1 in endometriotic tissues (ETs). (a) The AhR-ligand kynurenine. (b) Tryptophan (Trp) content in healthy endometrium (white) and ETs (black). The concentration is expressed as metabolite content/bioptic tissue mass (ng/g or $\mu / \mathrm{g}$, respectively), and the mean and s.d. from patients and controls $(n=9 / g r o u p)$ are shown. The $P$-values (*) reported in the plot area refer to Wilcoxon test. (c) Ratio between kynurenine and Trp in each individual analyzed. The concentration is expressed as the ratio of metabolite content normalized over bioptic tissue mass ( $\mathrm{ng} / \mathrm{\mu g}$ ). (d) Representative IDO1 immunostaining in healthy proliferative (i) and secretory (ii) endometrium and in ET (iii) are shown. Magnification, $\times 200$; (iv) show the significant differences in stromal $\mathrm{H}$-score values of IDO1 expression between ET samples and healthy endometrium ( $n=10 /$ group). The $P$-values $\left(^{*}\right)$ reported in the plot area refer to Wilcoxon test. 
a

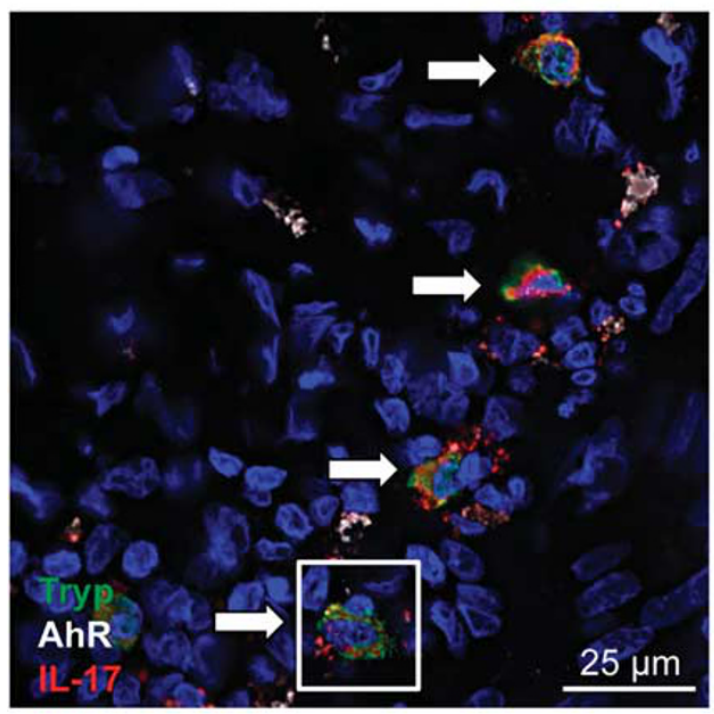

b

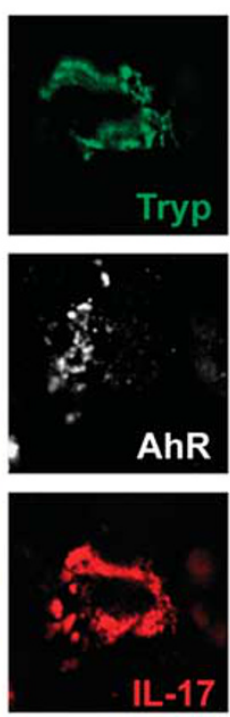

C

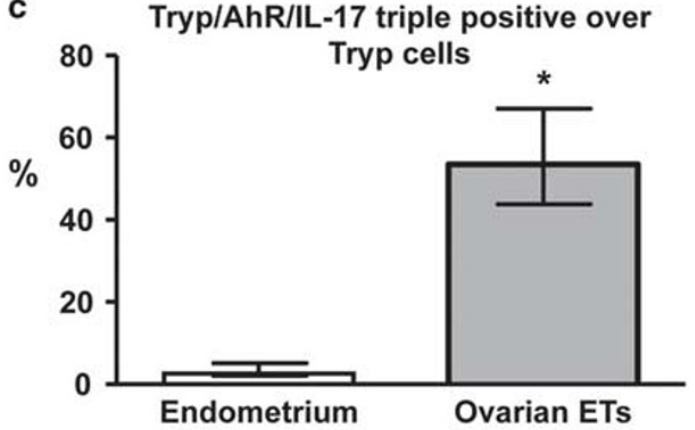

d

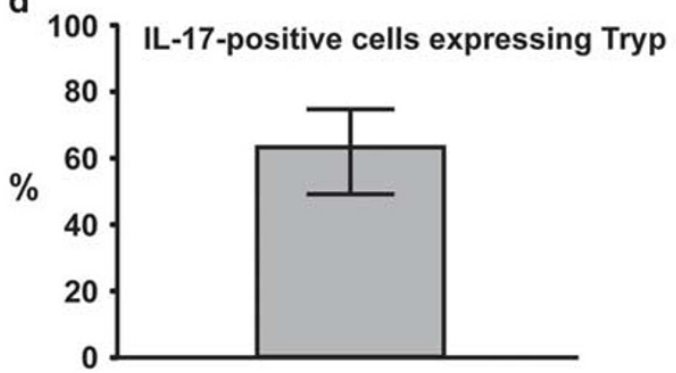

Figure 3 Aryl hydrocarbon receptor (AhR)-positive mast cells (MCs) express the inflammatory cytokine IL-17 in endometriotic tissues (ETs).

(a) Immunofluorescence triple staining showing that several tryptase-expressing MCs (Tryp, green) co-express both AhR (white) and IL-17 (red) (arrows). Scale bar, $25 \mu \mathrm{m}$. (b) A higher magnification view of the boxed area in (a) comparing uncoupled fluorescence micrographs of a MC. The DAPI staining shows that this field of cells is primarily a monolayer, allowing assessment of co-positivity for tryptase, AhR, and IL-17. (c) The percentage of triplepositive cells among tryptase-expressing MCs in 10 individual ET samples is shown. Cells were detected and counted from $10 \times 400$ high-power microscopic fields in each sample. Endometrium median 2.5\% (IQR 2-4\%); ovarian ET median 54\% (IQR 44-64\%). ${ }^{*}$ P $<0.05$ (Wilcoxon test). (d) IL-17 single-positive and IL-17 and tryptase double-positive cells were counted in ovarian ET samples as in (c). The results are expressed as the median of IL-17-positive cells expressing tryptase 63.0\% (IQR 49.0-74.5\%).

metabolizing enzyme IDO1 and a higher tissue concentration of the AhR-ligand kynurenine in ETs compared with the eutopic endometrium of controls. By contrast, tryptophan was significantly decreased in ETs compared with controls, supporting the interplay between AhR and kynurenine as a positive activator signal for MCs populating ETs. Finally, the involvement of $\mathrm{AhR}$ in the pathogenesis of endometriosis is supported by the observed down-modulation of several proinflammatory cytokines and chemokines, including IL-17 and IL-10, upon ET treatment with the AhR antagonist ANF, and the promotion of stromal cell growth by soluble factors released by MCs on AhR activation. However, due to the relatively small sample size, the results of this observational study must be interpreted with caution. Accordingly, validation of these findings in a larger independent cohort of patients is needed.

AhR was originally discovered as the mediator of the toxicity of environmental molecules. The effect of dioxin exposure on the risk of developing endometriosis remains controversial. In a non-human primate model, exposure to dioxin was associated with an increased prevalence and severity of endometriosis; ${ }^{42}$ similarly, several murine models support the possible role of environmental contaminants in the pathophysiology of endometriosis. ${ }^{6,43}$ However, a detailed review of the original epidemiological studies revealed no significant evidence supporting this relationship. ${ }^{44,45}$ Nevertheless, a proper understanding of the role of AhR in physiopathological conditions must differentiate between effects triggered by xenobiotic ligands and those triggered by endogenous ligands. A number of chemicals qualify as endogenous or physiological AhR ligands, including tryptophan products. ${ }^{46}$ Approximately $95 \%$ of ingested tryptophan enters the kynurenine pathway, and the first enzyme of the pathway is IDO1, which is stimulated by inflammatory molecules. ${ }^{47}$ The striking increase in kynurenine content in ETs compared with controls is consistent with the abundance of inflammatory cytokines observed here and in other diseases in which the immune response is activated and IFN- $\gamma$ is produced. ${ }^{48}$ Significant differences in tryptophan and its metabolites have been observed in the serum and plasma of patients with neurological disorders, affective disorders, autoimmune diseases and malignancy (reviewed in ref. 48); however, to our knowledge, this study is the first to report a high kynurenine/tryptophan ratio, which is also an index for IDO1 activity, in ETs compared with control tissues.

AhR plays critical modulatory roles in various immune cells during innate and adaptive immune responses, including MCs. Kynurenine promotes MC degranulation, lipid metabolite generation, and proinflammatory cytokine production $^{23}$ similar to 6 -formylindolo[3,2-b]carbazole 
a

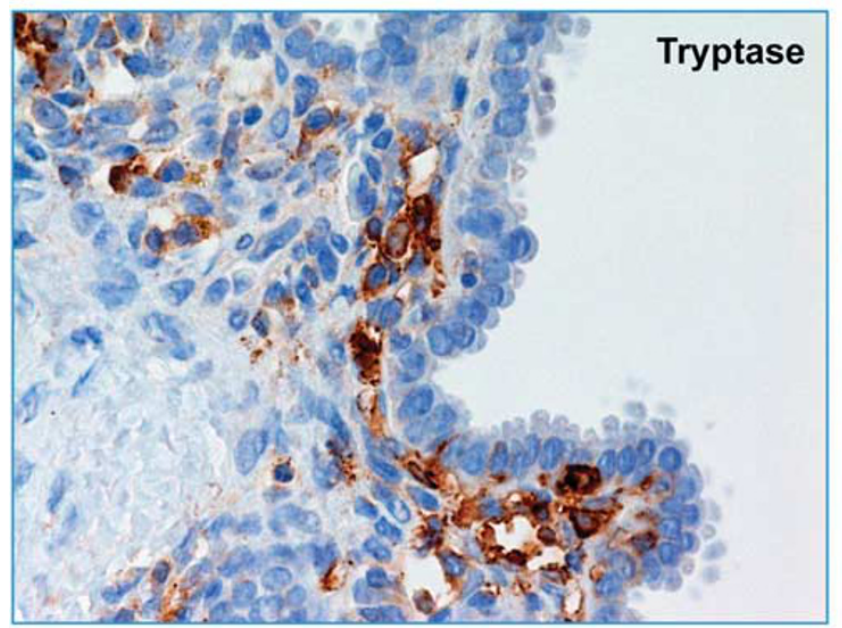

b

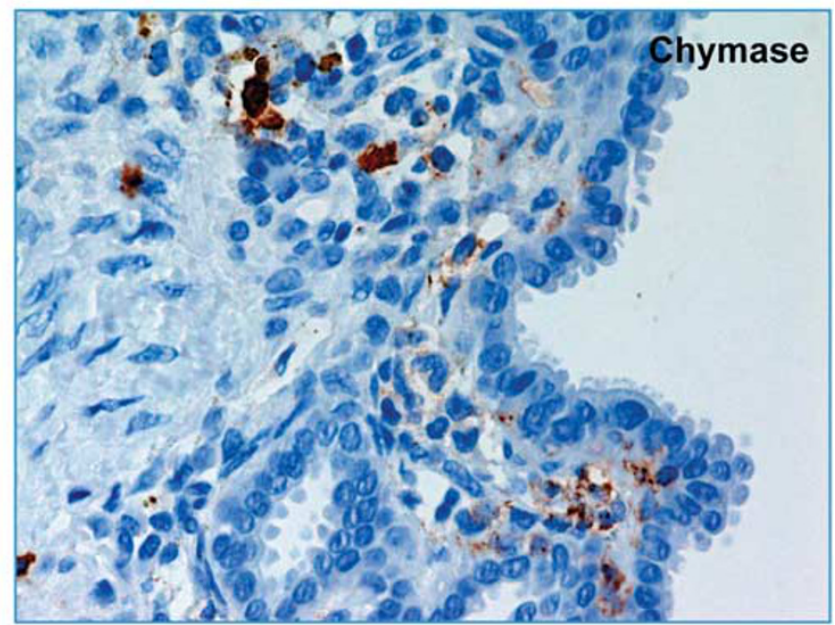

d

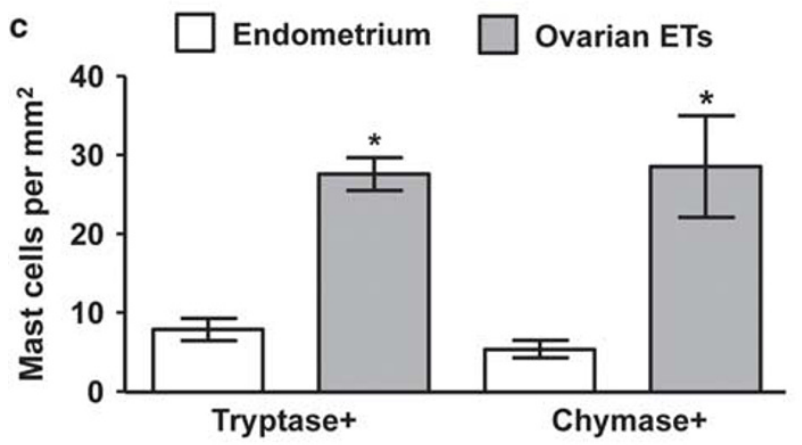

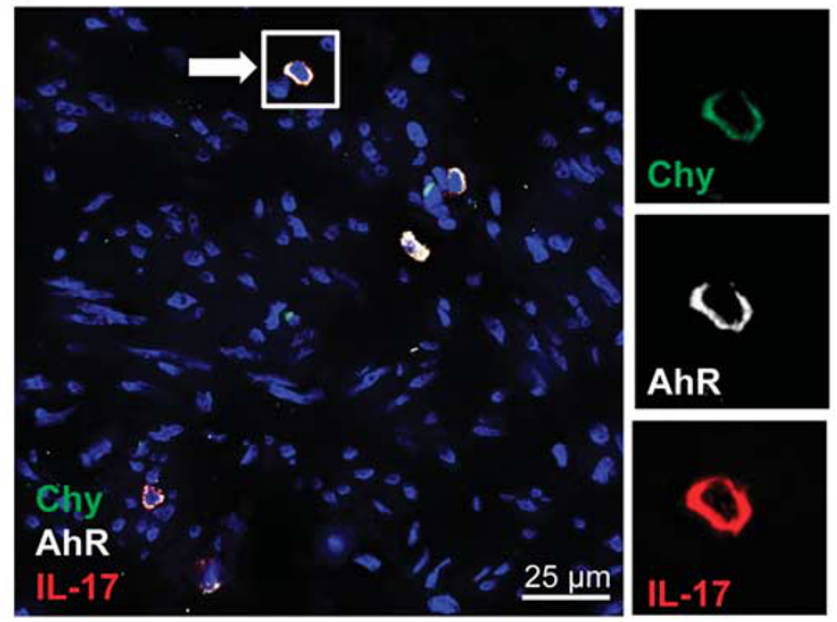

Figure 4 Chymase-expressing mast cells (MCs) within endometriotic tissues (ETs) are aryl hydrocarbon receptor (AhR)- and IL-17-positive. (a and b). Consecutive ET sections were cut and stained for MC tryptase and chymase, respectively. Magnification, $\times 400$. (c) Quantitative analysis of tryptase- and chymase-positive MCs. The data represent the mean \pm s.d. of the number of cells per $\mathrm{mm}^{2}$ observed in 10 fields of endometrium biopsies per specimen ( $n=8$ /group). ${ }^{*} P<0.05$ (Wilcoxon test). (d) Immunofluorescence triple staining showing that chymase-expressing MCs (Chy, green) co-express both AhR (white) and IL-17 (red) (arrows). Scale bar, $25 \mu \mathrm{m}$. On the right, a higher magnification view of the boxed area in (d) comparing uncoupled fluorescence micrographs of the selected MC.

(FICZ), which is produced on exposure of tryptophan to visible light or to UVA and UVB irradiation. ${ }^{49}$ Here, we were unable to measure FICZ compound levels in ETs or control eutopic tissues as it was below the detection limit of the ESI-MS assay (data not shown). Indeed, FICZ has only been identified in human skin, although FICZ-derived sulfate conjugates have been detected in human urine. ${ }^{18}$

Tissue-resident MCs can exert their effector functions through direct or indirect actions of a wide variety of preformed or newly synthesized and selectively released mediators, including histamine, proteases, leukotrienes, prostaglandins as well as numerous cytokines, neurotransmitters, and growth factors. This unique mediator profile might enable MCs to initiate an inflammatory cascade, leading to the observed symptoms of endometriosis. For example, it could modulate the recruitment, survival, development, phenotype, or function of other immune cells described to be involved in endometriosis pathology, including monocytes/macrophages. ${ }^{10,16}$ Macrophages are recruited to the peritoneal cavity, where they are likely to remove the retrograded endometrial debris in patients with endometriosis. ${ }^{5}$ They can be stimulated by soluble factors derived from endometriosis-derived stromal cells, such as IDO1-induced IL-33, to become polarized into M2 cells with decreased phagocytic ability. ${ }^{40,50}$ Endometrium-resident AhR-activated MCs, representing an early source of IL-10, could also promote peritoneal macrophage M2 polarization into a phenotype possessing tolerogenic activity. ${ }^{51}$ As a result, M2 cells dampen the immune response and support the survival of the ectopic endometrium in the initial stages of endometriosis. 
Moreover, concomitant MC production of IL-17, IL-6, and IL-10, together with peritoneal mesothelial cell-derived TGF- $\beta,{ }^{52}$ could drive regulatory $\mathrm{T}$ cells (Treg) to switch to chronic inflammatory Th17 lymphocytes. ${ }^{53}$ Furthermore, IDO1 activity could directly inhibit the proliferation and activation of effector $\mathrm{T}$ cells, thus inducing immune tolerance. ${ }^{54}$ a

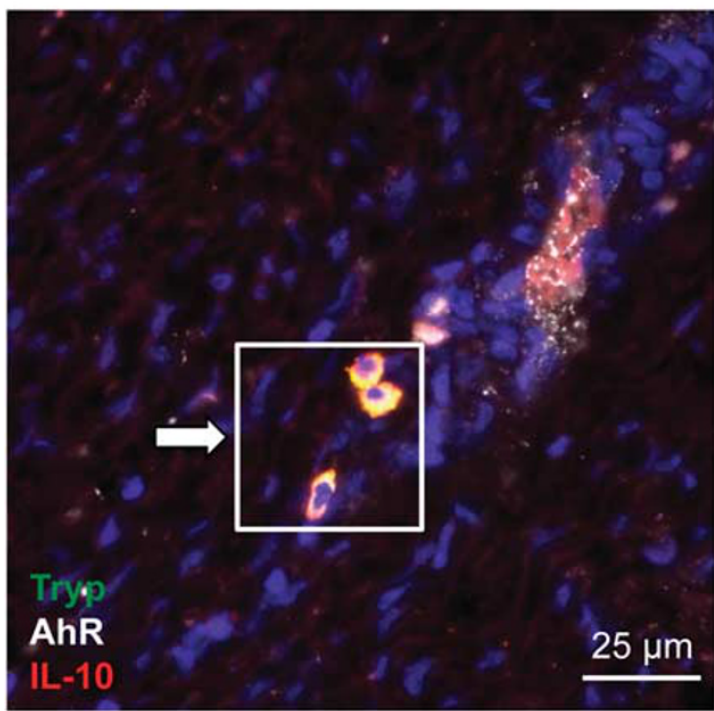

b

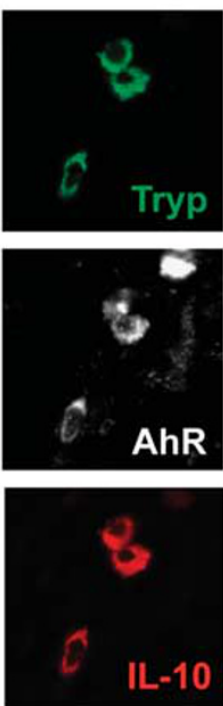

C

Tryp/AhR/IL-10 triple positive over Tryp cells

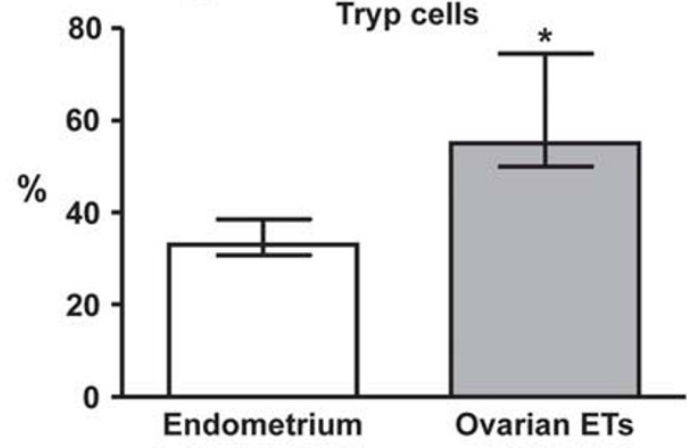

d

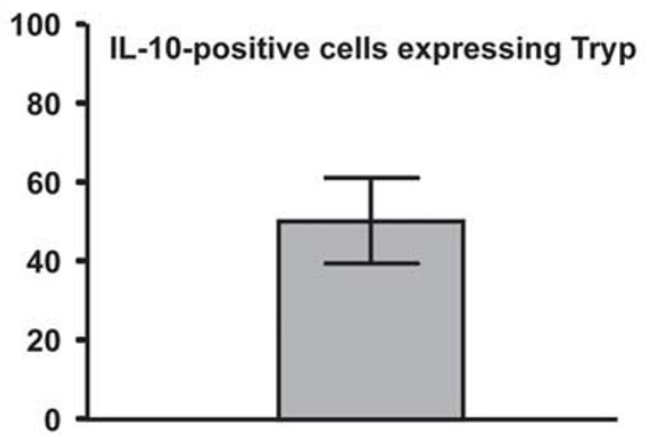

Figure 5 Aryl hydrocarbon receptor (AhR)-positive mast cells (MCs) express the tolerogenic IL-10 cytokine in endometriotic tissues (ETs).

(a) Immunofluorescence triple staining showing that several tryptase-expressing MCs (Tryp, green) co-express both AhR (white) and IL-10 (red) (arrows). Scale bar, $25 \mu \mathrm{m}$. (b) A higher magnification view of the boxed area in (a) comparing uncoupled fluorescence micrographs of three MCs. (c) The percentage of triple-positive cells among tryptase-expressing MCs in 10 individual control and ET samples is shown. Cells were detected and counted from $10 \times 400$ high-power microscopic fields in each sample. Endometrium median 33\% (IQR 31-37\%); ovarian median 55\% (IQR 53-73\%). ${ }^{*} P<0.05$ (Wilcoxon test). (d) IL-10 single-positive and IL-10 and tryptase double-positive cells were counted in ovarian ET samples as in c. IL-10 single-positive and IL-10 and tryptase double-positive cells were counted in ovarian ET samples as in (c). The results are expressed as the median of IL-10-positive cells expressing tryptase $50.2 \%$ (IQR 41.4-62.1\%).

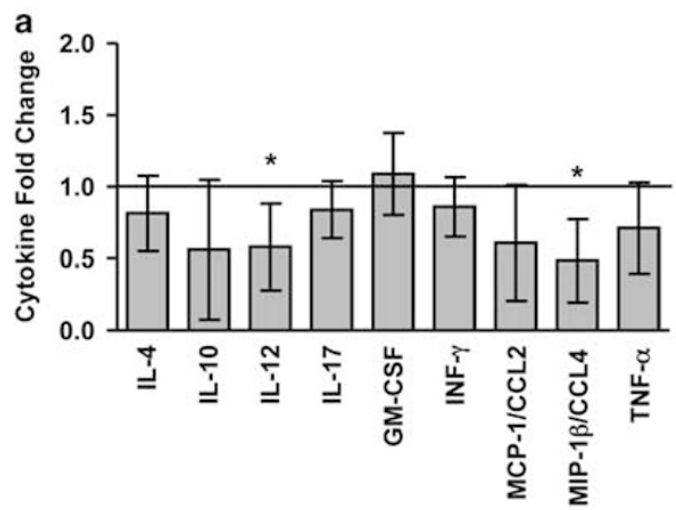

b

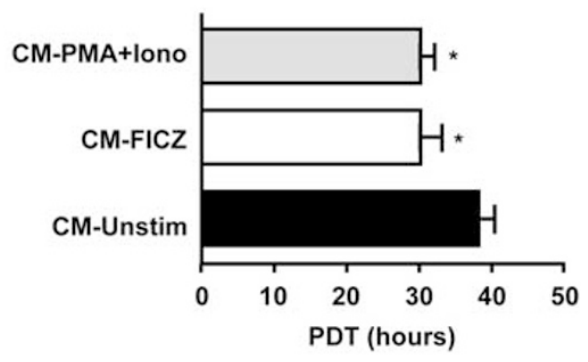

Figure 6 (a) Ovarian endometriotic tissues (ET) cytokine expression on treatment with an aryl hydrocarbon receptor (AhR) antagonist. IL-4, IL-10, IL-12, IL-17, GM-CSF, IFN- $\gamma$, MCP-1/CCL2, MIP-1 $\beta / C C L 4$, and TNF-a protein expression in supernatants of untreated (control) or ANF-treated ovarian ET cultures measured by ELISA $48 \mathrm{~h}$ after exposure to the AhR-antagonist ANF (15 $\mu \mathrm{M})$. Control protein concentration was assigned a value of 1 and is illustrated as a horizontal line for presentation purposes. Sample size was 4 patients/group. The values are the mean and $95 \%$ confidence intervals. ${ }^{*} P<0.05$ ( $t$-test).

(b) Reduced population doubling time (PDT) of endometrium stromal cells exposed to FICZ-activated MC-conditioned medium (CM). Endometriumderived stromal cells were cultured in CM of the HMC-1 MC line treated without (CM-Unstim) or with FICZ (CM-FICZ) or PMA and ionomycin (CM-PMA +lono) (for details, see Material and Methods section). Results are expressed as the median and IQR ( $n=3$ ), *P<0.05 (Dunn's Test) vs CM-Unstim. 
In response to AhR activation, MCs also produce reactive oxygen species $(\mathrm{ROS})^{17,22}$ that could contribute to the previously described enhanced ROS production in endometriotic cells, which promotes proliferative capabilities of the cells and favors the spreading of the disease. ${ }^{55}$

Anaf et al. ${ }^{12}$ found increased numbers of activated MCs near endometriotic lesions, often close to nerve fibers. It remains to be characterized whether MCs are able to sensitize primary nociceptive neurons by the release of nerve growth factor or proinflammatory cytokines in response to AhR activation, thus contributing directly to the development of pain in endometriosis.

To characterize the cytokine milieu present at ET sites and to determine any similarity with results at the periphery, we analyzed a broad range of cytokines produced by explant cultures of human endometrium, as performed by Osteen et al. ${ }^{56}$ Interestingly, as opposed to peritoneal fluid, we observed less TNF- $\alpha$ secretion from ETs than their healthy counterparts, a result that could explain why there is still insufficient evidence to support the use of anti-TNF- $\alpha$ drugs in the management of pelvic pain for women with endometriosis. ${ }^{57}$ Selective AhR modulators have been developed with a view to clinical applications, especially in the context of cancer. ${ }^{18}$ Considering the complexity of AhR signaling outcomes, the effectiveness of these drugs will depend on multiple factors, including dose and persistence. For instance, we have demonstrated that different $\mathrm{MC}$ responses can be achieved depending on the duration of FICZ stimulation. A single dose (that is, singular AhR activation) boosted proinflammatory features of MC activation (histamine and IL-6 production), whereas prolonged exposure shifted MCs toward IL-17 production and impaired degranulation. ${ }^{17}$ Thus, the short-term organ culture used in this study, which preserved epithelial-stromal and immune cell interactions, could represent a useful tool to assess the therapeutic potential of AhR ligands in modulating the proinflammatory environment of endometriosis, thus mediating disease progression.

Supplementary Information accompanies the paper on the Laboratory Investigation website (http://www.laboratoryinvestigation.org).

\section{ACKNOWLEDGMENTS}

We kindly thank Professor CA Beltrami for his expert advice and encouragement throughout this project. This work was supported by FIRB Pr. RBAP11Z4Z9; FIRB Pr. RBAP11ETKA_007; AIRC 5 per mille Pr. 12214; Project ERC-7FP SP 2 IDEAS QUIDPROQUO G.A. n. 269051; INTERREG GLIOMA; INTERREG PROTEO and Fondazione Cariplo, Milan. FIRB Pr. RBFR109EOS to MCM.

\section{DISCLOSURE/CONFLICT OF INTEREST}

The authors declare no conflict of interest.

1. Ferrero S, Arena E, Morando A et al. Prevalence of newly diagnosed endometriosis in women attending the general practitioner. Int $J$ Gynaecol Obstet 2010;110:203-207.

2. Giudice LC, Kao LC. Endometriosis. Lancet 2004;364:1789-1799.
3. Laufer MR. Current approaches to optimizing the treatment of endometriosis in adolescents. Gynecol Obstet Invest 2008;66:19-27.

4. Bulun SE. Endometriosis. N Engl J Med. 2009;360:268-279.

5. Herington JL, Bruner-Tran KL, Lucas JA et al. Immune interactions in endometriosis. Expert Rev Clin Immunol 2011;7:611-626.

6. Bruner-Tran KL, Yeaman GR, Crispens MA et al. Dioxin may promote inflammation-related development of endometriosis. Fertil Steril 2008;89:1287-1298.

7. Rao KN, Brown MA. Mast cells: multifaceted immune cells with diverse roles in health and disease. Ann N Y Acad Sci 2008;1143:83-104.

8. Gri G, Frossi $B, D^{\prime} I n c a ~ F$ et al. Mast cell: an emerging partner in immune interaction. Front Immunol 2012;1143:1-11.

9. Osuga $Y$, Koga K, Hirota $Y$ et al. Lymphocytes in endometriosis. Am J Reprod Immunol 2011;65:1-10.

10. Galli SJ, Grimbaldeston M, Tsai M. Immunomodulatory mast cells: negative, as well as positive, regulators of immunity. Nat Rev Immunol 2008;8:478-486.

11. Saito A, Osuga $Y$, Yoshino $O$ et al. TGF- $\beta 1$ induces proteinase-activated receptor 2 (PAR2) expression in endometriotic stromal cells and stimulates PAR2 activation-induced secretion of IL-6. Hum Reprod 2011;26:1892-1898.

12. Anaf V, Chapron C, El Nakadi I et al. Pain, mast cells, and nerves in peritoneal, ovarian, and deep infiltrating endometriosis. Fertil Steril 2006;86:1336-1343.

13. Matsuzaki $S$, Canis $M$, Darcha $C$ et al. Increased mast cell density in peritoneal endometriosis compared with eutopic endometrium with endometriosis. Am J Reprod Immunol 1998;40:291-294.

14. Sugamata $M$, Ihara $T$, Uchiide I. Increase of activated mast cells in human endometriosis. Am J Reprod Immunol 2005;53:120-125.

15. Paula $\mathrm{R}$, Oliani $\mathrm{AH}$, Vaz-Oliani DCM et al. The intricate role of mast cell proteases and the annexin A1-FPR1 system in abdominal wall endometriosis. J Mol Histol 2015;46:33-43.

16. Kirchhoff $D$, Kaulfuss $S$, Fuhrmann $U$ et al. Mast cells in endometriosis: guilty or innocent bystanders? Expert Opin Ther Targets 2012;16: 237-241.

17. Sibilano R, Frossi B, Calvaruso $M$ et al. The aryl hydrocarbon receptor modulates acute and late mast cell responses. J Immunol 2012;189: 120-127.

18. Esser C, Rannug A. The aryl hydrocarbon receptor in barrier organ physiology, immunology, and toxicology. Pharmacol Rev 2015;67:259-279.

19. Brusselle GG, Joos GF, Bracke KR. New insights into the immunology of chronic obstructive pulmonary disease. Lancet 2011;378:1015-1026.

20. Monteleone I, Rizzo A, Sarra M et al. Aryl hydrocarbon receptorinduced signals up-regulate IL-22 production and inhibit inflammation in the gastrointestinal tract. Gastroenterology 2011;141:237-248.

21. Stockinger B, Hirota K, Duarte J et al. External influences on the immune system via activation of the aryl hydrocarbon receptor. Semin Immunol. 2011;23:99-105.

22. Zhou Y, Tung H-Y, Tsai Y-M et al. Aryl hydrocarbon receptor controls murine mast cell homeostasis. Blood 2013;121:3195-3204.

23. Kawasaki $\mathrm{H}$, Chang $\mathrm{H}-\mathrm{W}$, Tseng $\mathrm{H}-\mathrm{C}$ et al. A tryptophan metabolite, kynurenine, promotes mast cell activation through aryl hydrocarbon receptor. Allergy 2014;69:445-452.

24. Pilz C, Feyerabend $T$, Sonner $J$ et al. Normal mast cell numbers in the tissues of AhR-deficient mice. Exp Dermatol 2016;25:62-63.

25. Zhao D, Pritts EA, Chao VA et al. Dioxin stimulates RANTES expression in an in-vitro model of endometriosis. Mol Hum Reprod 2002;8:849-854.

26. Küchenhoff A, Seliger $G$, Klonisch $T$ et al. Arylhydrocarbon receptor expression in the human endometrium. Fertil Steril. 1999;71:354-360.

27. Hernández-Ochoa I, Karman BN, Flaws JA. The role of the aryl hydrocarbon receptor in the female reproductive system. Biochem Pharmacol 2009;77:547-559.

28. Khorram O. Uterine and ovarian aryl hydrocarbon receptor (AHR) and aryl hydrocarbon receptor nuclear translocator (ARNT) mRNA expression in benign and malignant gynaecological conditions. Mol Hum Reprod 2002;8:75-80.

29. Pitt JA, Feng L, Abbott BD et al. Expression of AhR and ARNT mRNA in cultured human endometrial explants exposed to TCDD. Toxicol Sci 2001;62:289-298.

30. Calcagno A, Grassi T, Mariuzzi $L$ et al. Expression patterns of Aurora A and $\mathrm{B}$ kinases, $\mathrm{Ki}-67$ and the estrogen and progesterone receptors determined using an endometriosis tissue microarray model. Hum Reprod 2011;26:2731-2741. 
31. Hossain A, Tsuchiya $S$, Minegishi $M$ et al. The Ah Receptor is not involved in 2,3,7,8-tetrachlorodibenzo- p-dioxin-mediated apoptosis in human leukemic T cell lines. J Biol Chem 1998;273:19853-19858.

32. Beltrami AP, Cesselli $\mathrm{D}$, Bergamin $\mathrm{N}$ et al. Multipotent cells can be generated in vitro from several adult human organs (heart, liver, and bone marrow). Blood 2007;110:3438-3446.

33. Bergamin N, Dardis A, Beltrami A et al. A human neuronal model of Niemann Pick $C$ disease developed from stem cells isolated from patient's skin. Orphanet J Rare Dis. 2013;8:34.

34. Domenis R, Bergamin N, Gianfranceschi $G$ et al. The redox function of APE1 is involved in the differentiation process of stem cells toward a neuronal cell fate. PLoS One 2014;9:e89232.

35. Nilsson G, Svensson V, Nilsson K. Constitutive and inducible cytokine mRNA expression in the human mast cell line HMC-1. Scand J Immunol 1995;42:76-81.

36. Pizzo A, Salmeri FM, Ardita F V et al. Behaviour of cytokine levels in serum and peritoneal fluid of women with endometriosis. Gynecol Obstet Invest 2002;54:82-87.

37. Kalu E, Sumar N, Giannopoulos T et al. Cytokine profiles in serum and peritoneal fluid from infertile women with and without endometriosis. J Obstet Gynaecol Res 2007;33:490-495.

38. Esser C, Rannug A, Stockinger B. The aryl hydrocarbon receptor in immunity. Trends Immunol 2009;30:447-454.

39. Harper PA, Riddick DS, Okey AB. Regulating the regulator: factors that control levels and activity of the aryl hydrocarbon receptor. Biochem Pharmacol 2006;72:267-279.

40. Mei J, Jin L-P, Ding $D$ et al. Inhibition of IDO1 suppresses cyclooxygenase-2 and matrix metalloproteinase-9 expression and decreases proliferation, adhesion and invasion of endometrial stromal cells. Mol Hum Reprod 2012;18:467-476.

41. Henry EC, Kende AS, Rucci $G$ et al. Flavone antagonists bind competitively with 2,3,7,8-tetrachlorodibenzo-p-dioxin (TCDD) to the aryl hydrocarbon receptor but inhibit nuclear uptake and transformation. Mol Pharmacol 1999;55:716-725.

42. Rier SE, Martin DC, Bowman RE et al. Endometriosis in rhesus monkeys (Macaca mulatta) following chronic exposure to 2,3,7,8-tetrachlorodibenzo-p-dioxin. Fundam Appl Toxicol 1993;21:433-441.

43. Caserta D, Maranghi L, Mantovani A et al. Impact of endocrine disruptor chemicals in gynaecology. Hum Reprod Update 2008;14: 59-72.
44. Sofo V, Götte M, Laganà AS et al. Correlation between dioxin and endometriosis: an epigenetic route to unravel the pathogenesis of the disease. Arch Gynecol Obstet 2015;292:973-986.

45. Guo S-W, Simsa P, Kyama CM et al. Reassessing the evidence for the link between dioxin and endometriosis: from molecular biology to clinical epidemiology. Mol Hum Reprod 2009;15:609-624.

46. Denison MS, Nagy SR. Activation of the aryl hydrocarbon receptor by structurally diverse exogenous and endogenous chemicals. Annu Rev Pharmacol Toxicol 2003;43:309-334.

47. Zhu W, Stevens AP, Dettmer K et al. Quantitative profiling of tryptophan metabolites in serum, urine, and cell culture supernatants by liquid chromatography-tandem mass spectrometry. Anal Bioanal Chem 2011;401:3249-3261.

48. Chen Y, Guillemin GJ. Kynurenine pathway metabolites in humans: disease and healthy States. Int J Tryptophan Res 2009;2:1-19.

49. Wincent $E$, Amini $N$, Luecke $S$ et al. The suggested physiologic aryl hydrocarbon receptor activator and cytochrome P4501 substrate 6-formylindolo[3,2-b]carbazole is present in humans. J Biol Chem 2009:284:2690-2696

50. Mei J, Xie X-X, Li M-Q et al. Indoleamine 2,3-dioxygenase-1 (IDO1) in human endometrial stromal cells induces macrophage tolerance through interleukin-33 in the progression of endometriosis. Int J Clin Exp Pathol 2014;7:2743-2757.

51. Sica A, Mantovani A. Macrophage plasticity and polarization: in vivo veritas. J Clin Invest 2012;122:787-795.

52. Young VJ, Brown JK, Saunders PTK et al. The peritoneum is both a source and target of TGF- $\beta$ in women with endometriosis. PLoS One 2014;9:1-10.

53. McGeachy MJ, Bak-Jensen KS, Chen $Y$ et al. TGF-beta and IL- 6 drive the production of IL-17 and IL-10 by $\mathrm{T}$ cells and restrain $\mathrm{T}(\mathrm{H})-17$ cellmediated pathology. Nat Immunol 2007;8:1390-1397.

54. Jaronen M, Quintana FJ. Immunological relevance of the coevolution of IDO1 and AHR. Front Immunol 2014:5:521.

55. Ngô C, Chéreau C, Nicco $C$ et al. Reactive oxygen species controls endometriosis progression. Am J Pathol 2009;175:225-234.

56. Osteen KG, Rodgers WH, Gaire $M$ et al. Stromal-epithelial interaction mediates steroidal regulation of metalloproteinase expression in human endometrium. Proc Natl Acad Sci USA 1994;91:10129-10133.

57. Lu D, Song H, Shi G. Anti-TNF-a treatment for pelvic pain associated with endometriosis. Cochrane database Syst Rev 2013;3:1-29. 